\title{
TÉCNICA DE DEFENSA CONSTITUCIONAL ANTE LOS FORMALISMOS PROCESALES DEL NUEVO SISTEMA GENERAL DE RESPONSABILIDADES ADMINISTRATIVAS PARA SERVIDORES PÚBLICOS Y PARTICULARES
}

\author{
David Alejandro Parada SÁnchez ${ }^{1}$
}

RESUmen: El presente artículo consiste en un análisis del nuevo modelo de Responsabilidad Administrativa de Servidores Públicos y Particulares, derivado de la Ley General de Responsabilidades Administrativas, publicada en dieciocho de julio de dos mil dieciséis, con un enfoque crítico desde la técnica jurídica, para establecer métodos y estrategias para garantizar un ejercicio pleno de una defensa adecuada para el infractor, superando las formalidades procesales.

A través de un método analítico, sistemático, comparativo y deductivo, se establecerán los parámetros de defensa que pueden intentarse, utilizando herramientas normativas como lo es la propia Ley General de Responsabilidades Administrativas, Ley de Amparo y las disposiciones vigentes que rigen el Tribunal Federal de Justicia Administrativa; además, de las jurisprudencias emitidas por el Poder Judicial de la Federación.

Las anteriores normas enlistadas, serán sujetas de un análisis hermenéutico crítico, para definir la procedencia e improcedencia de medios de defensa, así como, la naturaleza de los actos de autoridad, para verificar conclusivamente la validez sustancial de los formalismos procesales, que incluso, podrían tener como consecuencia, una negativa formal de acceso a la justicia.

Palabras clave: Acceso a la justicia, responsabilidad administrativa, procedimiento administrativo, medio de defensa, juicio de amparo, formalismos procesales, defensa adecuada y validez sustancial de la norma.

ABSTRACT: This article consists of an analysis of the new model of Administrative Responsibility of Public and Private Servants,

1 Maestro en Derecho por la Universidad Nacional Autónoma de México y en su sede Facultad de Estudios Superiores Acatlán; así como, profesor en la Licenciatura de Derecho y del Programa de Posgrado de Derecho en la misma institución. 
derived from the General Law of Administrative Responsibilities, published on July eighteen of two thousand sixteen, with a critical approach from the legal technique, to establish methods and strategies to guarantee a full exercise of an adequate defense for the offender, overcoming the procedural formalities.

Through an analytical, systematic, comparative and deductive method, the defense parameters that can be attempted will be established, using normative tools such as the General Law of Administrative Responsibilities, the Amparo Law and the current provisions that govern the Federal Court of Justice. Administrative Justice; in addition, of the jurisprudence issued by the Judicial Power of the Federation.

The aforementioned norms will be subject to a critical hermeneutical analysis, to define the origin and inappropriateness of defense means, as well as, the nature of the acts of authority, to conclusively verify the substantial validity of procedural formalities, which could even have as a consequence, a formal refusal of access to justice.

KEYWORDS: Access to justice, administrative responsibility, administrative procedure, means of defense, amparo proceedings, procedural formalities, adequate defense and substantial validity of the norm.

SUmARIO: I. Introducción; II. El derecho de acceso a la justicia. III. El procedimiento administrativo y el procedimiento jurisdiccional; IV. Nuevo modelo de proceso de responsabilidad administrativa; V. Procedencia del Juicio de Amparo contra actos de autoridades administrativas; VI. Medios de Impugnación en el procedimiento de responsabilidad administrativa; VII. Técnica Jurídica y Argumentación; VIII. La validez de la norma y los formalismos procesales; IX. Conclusiones; X. Bibliografía.

\section{INTRODUCCIÓN}

11 régimen de responsabilidad de servidores públicos es una figura jurídica de suma relevancia para cualquier sistema jurídico democrático, incluso podemos afirmar que es un elemento esencial para calificar como válido a un sistema jurídico moderno. 
La relevancia de un régimen especial para servidores públicos, deriva de la delicada función que les ha sido encomendada, que es la vinculación con la prestación de servicios públicos y el manejo directo o indirecto de recursos públicos. Por lo tanto, su actividad es un elemento eficiente que trasciende en el buen funcionamiento de la Administración Pública, que se encuentra estrechamente vinculada al bienestar social, desde un punto de vista político, jurídico, económico y social.

Así, la expectativa que tenemos como ciudadanos respecto de la labor del servidor público, es que sea eficiente, eficaz, legal, transparente, servicial, y sobre todo, respetuosa de nuestros derechos fundamentales. Por ello, resulta normal que la conducta de los servidores públicos se encuentre en constante escrutinio.

En nuestro sistema jurídico, el régimen de responsabilidad para los servidores públicos ha estado en constante construcción a través de la norma y los criterios emitidos por el Poder Judicial de la Federación. Desde el constituyente de 1917 fue considerada la relevancia de su conducta, al establecer parámetros de actuación para los mismos, así como, organismos enfocados a regular dicho ámbito, como lo podemos observar en el Titulo Cuarto, titulado De las Responsabilidades de los Funcionarios Públicos y a partir de ese momento, constantemente este ámbito ha sido sujeto de innumerables modificaciones, en los distintos niveles de gobierno.

Sin embargo, el constituyente no previó un fenómeno al que hoy día todos nos encontramos, la implantación del modelo neoliberal, no sólo en el ámbito económico, sino también en el político, social y claro, el jurídico. Y así como se pretendió la desregulación y liberalización del mercado, también la sociedad se ha liberalizado. ${ }^{2}$

En lo que nos atañe, el neoliberalismo ha tenido dos efectos relevantes, uno jurídico y otro social. En el plano jurídico, ante la

2 Dag Einar Thorsen and Amund Lie. What is Neoliberalism?, Department of Political Science University of Oslo, Noruega, p.2., consultado en < http://folk.uio.no/daget/ What $\% 20$ is $\% 20$ Neo-Liberalism\%2010-11-06.pdf $>$. 
apertura de los mercados y su crecimiento, así como, la presión de los mismos para lograr el Estado Mínimo a que se refiere Milton Friedman, ${ }^{3}$ los particulares poco a poco han logrado inmiscuirse en actividades propias del Estado Mexicano.

De esa forma, tenemos actividades del ámbito público que se han puesto en manos de los particulares, como lo es, la obra pública, la prestación del servicio de energía o las telecomunicaciones; asimismo, particulares que prestan conjuntamente con el gobierno servicios públicos, como lo son, los servicios subrogados en el ámbito médico o la educación. Así, es como llegamos al caso de que los propios particulares se ocupan de aplicar recursos públicos.

Por otro lado, el neoliberalismo ha impactado el ámbito social, ha fortalecido el constante crecimiento de la corrupción en una sociedad mexicana donde los estándares educativos son bajos, conjugado con una visión materialista de la vida y una cosificación de las personas implantada por el propio mercado global. Evidentemente, esos elementos han hecho de México un territorio fértil para la corrupción en todos los ámbitos sociales.

Ambos fenómenos han generado que nuestro país esté considerado entre los países con mayores niveles de corrupción, y no sólo por parte de los servidores públicos, también los particulares que cumplen con alguna función o fin público. Tal y como se refiere en la iniciativa de la Ley General del Sistema Nacional Anticorrupción (2015)

De acuerdo al último informe del Índice de Percepción de la Corrupción, elaborado por la organización Transparencia Internacional en 2014, nuestro país ocupa el lugar número 103 del índice de corrupción de 175 naciones, lo que hace necesario redoblar esfuerzos en el establecimiento de medidas institucionales tendientes a prevenir, detectar y sancionar las conductas relacionadas con actos de corrupción en los diversos ámbitos de gobierno. ${ }^{4}$

3 Idem, p. 8-11.

4 Grupo parlamentario del Partido Acción Nacional en la Cámara de Senadores Exposición de Motivos para la Iniciativa con proyecto de decreto por el que se expide la Ley General del Sistema Nacional Anticorrupción, México, 2015. 
Así, en México el régimen de responsabilidad para servidores públicos se vio superado, por la impunidad, la falta de preparación de los órganos de control, la debilidad de las instituciones fiscalizadoras, procedimientos endebles y la misma corrupción dentro de los propios órganos disciplinarios.

Ante esa realidad, surge en el año 2016 las reformas consideradas como parte de la implementación del Sistema Nacional Anticorrupción y entre las distintas normas, se crea la Ley General de Responsabilidades Administrativas, con el objeto de "conducir a prevenir y, en su caso, a identificar y sancionar las redes de la corrupción, impidiendo que quienes las conforman puedan seguir medrando con las atribuciones o los recursos públicos."

Con esa novedosa reforma, se implementó en nuestro sistema jurídico un nuevo procedimiento para investigar y sancionar conductas que se consideran faltas administrativas, con aplicación para servidores públicos y particulares.

Evidentemente el nuevo proceso administrativo de responsabilidad administrativa contiene diversas formalidades procesales, que en nuestro sistema jurídico provocan un cambio en la técnica jurídica del abogado y los juzgadores para aplicar la norma, asimismo, trasciende en los medios de defensa ordinarios y extraordinarios. $\mathrm{Al}$ igual, son visibles formalismos procesales que podrían ser violatorios del derecho de defensa adecuada.

En el artículo que se tiene a la vista, se pretende plantear la técnica jurídica para ejercer un adecuado derecho de defensa, conforme a las formalidades del novedoso procedimiento administrativo, asimismo, evidenciar los formalismos procesales que podrían generar un estado de indefensión, si es que no son comprendidos.

5 Cortés Campos, Josefina, Kaiser Aranda Max y Roldá Xopa, José, Iniciativa Ciudadana de la Ley General de Responsabilidades Administrativas, México, recuperado el 25 de octubre de 2017, de <http://ley3de3.mx/wp-content/uploads/2016/02/Ley3de3_LEY_IniciativaCiudadanaDeLeyGeneralDeResponsabilidadesAdministrativas_Documento.pdf $>$. 
Por lo tanto, será analizado el derecho de acceso a la justicia, para poder contrastar el mismo, con las formalidades y los formalismos del procedimiento administrativo de responsabilidad de servidores públicos, para que una vez entablada la técnica jurídica, podamos asumir la tarea de formular propuestas que permitan dar un acceso efectivo a la justicia.

\section{El derecho de acceso A la justicia}

En el ámbito internacional, el derecho de acceso a la justicia está previsto en la Convención Americana sobre Derechos Humanos "Pacto de San José", en sus artículos 7o., 8o. y 25. ${ }^{6}$ El nuestra Constitución se prevé en el artículo 17, en el que se prevé como el derecho que tiene toda persona a que se le administre justicia, precisa sus características y parámetros de la siguiente manera:

Toda persona tiene derecho a que se le administre justicia por tribunales que estarán expeditos para impartirla en los plazos y términos que fijen las leyes, emitiendo sus resoluciones de manera pronta, completa e imparcial. Su servicio será gratuito, quedando, en consecuencia, prohibidas las costas judiciales.

Siempre que no se afecte la igualdad entre las partes, el debido proceso u otros derechos en los juicios o procedimientos seguidos en forma de juicio, las autoridades deberán privilegiar la solución del conflicto sobre los formalismos procedimentales. ${ }^{7}$

Entendamos que la administración de justicia, desde el marco constitucional, no equivale a una concepción filosófica o teórica de la justicia, sino a una connotación de un servicio jurisdiccional, esto es, que se trata del derecho que tiene todo ser humano de acudir

6 Convención Americana sobre Derechos Humanos "Pacto de San José", adoptada en San José Costa Rica el 22 de noviembre de 1969, aprobada por el Senado el 18 de diciembre de 1980, publicación: DOF, 7 de mayo de 1981.

7 Artículo 17, Gonstitución Política de los Estados Unidos Mexicanos, vigente al día 25 de octubre de 2017. 
ante una autoridad jurisdiccional, para que dentro de su competencia satisfaga la necesidad de que sea solucionado el problema que se le plantea.

Correlativamente, las autoridades jurisdiccionales tienen el deber constitucional para que dentro de su ámbito de competencia, dé una solución válida al problema que le fue planteado, lo cual, no significa que necesariamente se le tenga que dar la razón a quien ejercitó el mencionado derecho. Incuso, este derecho va más allá de la emisión de unas sentencia, pues la misma debe ser ejecutada.

Este derecho tiene parámetros constitucionales como lo es que sea expedita, es decir, libre de todo estorbo. ${ }^{8}$ Se debe impartir en los plazos y términos que fijen las leyes, lo cual forma parte del fundamento constitucional de las normas procesales de nuestro país, así que, este parámetro se cumplirá cuando el Juzgador resuelva el conflicto estrictamente en la temporalidad que marque la ley procesal de su materia. Hasta aquí, los parámetros del procedimiento jurisdiccional.

Por otro lado, nos da los parámetros que deberán satisfacer sus resoluciones. Que deberán ser emitidas de manera pronta, completa e imparcial. La prontitud, al igual que en el anterior párrafo, su parámetro será el tiempo que marquen las normas procesales. El parámetro de completa, se vincula a las reglas de congruencia interna y externa, así como, de exhaustividad.

Esto es, que las resoluciones que se emitan deben ser armónicas y lógicas con su propio contenido, coherentes con los planteamientos realizados por el justiciable y que todos y cada uno de los puntos peticionados y argumentados por el ciudadano sean atendidos en esas resoluciones, con el objeto de cumplir con un parámetro de satisfacción.

8 Definición de expedito, Diccionario de la Real Academia Española (2017) España, recuperado de $<$ http://dle.rae.es/?id=HIPgcQm $>$. 
En cuanto a la imparcialidad, Ovalle Fabela (2011), refiere que es "una condición esencial para el ejercicio de la función jurisdiccional... esa condición de ajeneidad que el juez y los magistrados deben tener respecto de los intereses de las partes en conflicto". ${ }^{9}$

Como último parámetro que tenemos, es la gratuidad del servicio que presten los Tribunales, ello con la finalidad de no condicionar el ejercicio de este derecho a la situación o posición económica de cada persona, logrando un parámetro de igualdad. Los anteriores son parámetros sobre los cuales todo Tribunal y Juzgador deberá apegarse.

Siguiendo la teoría de los derechos fundamentales, explicada por Luigi Ferrajoli, quien nos destaca que todo derecho fundamental trae aparejado una serie de garantías, que permiten su pleno acceso, ejercicio, protección e incluso reparación. ${ }^{\circ}$ Así, el derecho de acceso a la justicia tiene aparejadas una serie de garantías, así como, interdependencia de otros derechos fundamentales. Entre los primeros podemos destacar el debido proceso, audiencia, segunda instancia, presunción de inocencia; entre los segundos, seguridad jurídica, legalidad e igualdad.

El Primer Tribunal Colegiado en Materia Administrativa del Sexto Circuito, establece cuáles son las garantías que conlleva el derecho de acceso a la justicia de la siguiente manera:

Las garantías mencionadas subyacen en el derecho fundamental de acceso a la justicia previsto en el artículo 17 constitucional, y detallan sus alcances en cuanto establecen lo siguiente: 1. El derecho de toda persona a ser oída con las debidas garantías y dentro de un plazo razonable, por un Juez o tribunal competente, independiente e imparcial, establecido con anterioridad por la ley, en la sustanciación de cualquier acusación penal formulada contra ella

9 Ovalle Favela, José. Teoría general del proceso, 6 $6^{\text {a }}$ edición, Oxford, México, 2011 p. 147 .

10 Ferrajoli, Luigi, Los fundamentos de los derechos fundamentales, España $4^{\mathrm{a}}$. ed., trad. Andrés Perfecto, Antonio de Cabo, et al., Trotta, 2009, p. 45 y 46. 
o para la determinación de sus derechos y obligaciones de orden civil, laboral, fiscal o de cualquier otro carácter; 2. La existencia de un recurso judicial efectivo contra actos que violen derechos fundamentales; 3 . El requisito de que sea la autoridad competente prevista por el respectivo sistema legal quien decida sobre los derechos de toda persona que lo interponga; 4. El desarrollo de las posibilidades de recurso judicial; y, 5. El cumplimiento, por las autoridades competentes, de toda decisión en que se haya estimado procedente el recurso. ${ }^{11}$

\section{EL PROCEDIMIENTO ADMINISTRATIVO Y EL PROCEDIMIENTO JURISDICCIONAL}

El artículo 14 constitucional nos establece la garantía del debido proceso legal, al señalar expresamente que "nadie podrá ser privado de la libertad o de sus propiedades, posesiones o derechos, sino mediante juicio seguido ante los tribunales previamente establecidos, en el que se cumplan las formalidades esenciales del procedimiento y conforme a las Leyes expedidas con anterioridad al hecho." 12

Como principio constitucional, nos establece un parámetro de optimización que resulta ser en las formalidades esenciales del procedimiento, caracterizado por una etapa postulatoria, probatoria, conclusiva, de juicio e impugnativa. Así, en todo procedimiento seguido ante los Tribunales deben ser respetadas esas formalidades. Al tratarse solo de parámetros, el legislador podrá establecer actos procesales específicos para cada materia y según la naturaleza del procedimiento; las cuales, no deben ser excesivas, de lo contrario

11 Primer Tribunal Colegiado en Materia Administrativa del Sexto Circuito, (2012) jurisprudencia VI.1o.A. J/2 (10a.), publicada en Semanario Judicial de la Federación y su Gaceta, Décima Época, Libro XI, Agosto de 2012, Tomo 2, p. 1096.

12 Artículo 14, Constitución Política de los Estados Unidos Mexicanos, vigente al día 25 de octubre de 2017. 
pasaríamos de formalidades a formalismos, lo cual analizaremos más adelante.

El procedimiento que nos hemos estado refiriendo es bajo la connotación de juicio, el cual solo se desarrolla ante los Tribunales; mas no es el único tipo de procedimiento que se debe apegar a las mismas, que ante autoridades administrativas se pueden desarrollar procedimientos administrativos en forma de juicio.

Por lo que debemos distinguir entre un procedimiento administrativo y un procedimiento administrativo llevado en forma de juicio, distinción que se realiza en el artículo 108, fracción III, de la Ley de Amparo; lo cual, es relevante analizamos los derechos procesales, así como, el momento en que es procedente el Juicio de Amparo.

Un procedimiento administrativo seguido en forma de juicio se considerará como tal, sólo en dos casos: cuando en el procedimiento seguido en instancia administrativa tenga por objeto dirimir una controversia entre partes contendientes, es decir, se configura un litigio; o bien, cuando la autoridad administrativa emitirá una resolución en la que se requiera darle garantía de audiencia al particular que resentirá la misma, es decir, en el que se deban observar las formalidades esenciales del procedimiento. Así lo podemos apreciar en la opinión de la Segunda Sala de la Suprema Corte de Justicia de la Nación:

PROCEDIMIENTOS EN FORMA DE JUICIO SEGUIDOS POR AUTORIDADES DISTINTAS DE TRIBUNALES A QUE SE REFIERE EL ARTÍCULO 114, FRACGIÓN II, PÁRRAFO SEGUNDO, DE LA LEY DE AMPARO. SU GONCEPTO COMPRENDE TANTO AQUELLOS EN QUE LA AUTORIDAD DIRIME UNA CONTROVERSIA ENTRE PARTES GONTENDIENTES, COMO LOS PROCEDIMIENTOS MEDIANTE LOS QUE LA AUTORIDAD PREPARA SU RESOLUCIÓN DEFINITIVA CON INTERVENGIÓN DEL PARTICULAR. La Ley de Amparo establece que tratándose de actos dentro de un procedimiento, la regla general, con algunas excepciones, es que el juicio constitucional sólo procede hasta la resolución definitiva, ocasión en la cual cabe alegar tanto violaciones de fondo como de procedimiento, sistema que tiene el 
propósito de armonizar la protección de las garantías constitucionales del gobernado, con la necesidad de asegurar la expeditez de las diligencias procedimentales. Tal es la estructura que dicha Ley adopta en el amparo directo, así como en los procedimientos de ejecución y en los procedimientos de remate, como lo establece en sus artículos 158 y 114, fracción III, respectivamente. Por tanto, al establecer el segundo párrafo de la fracción II del artículo 114 acabado de citar, que cuando el acto reclamado de autoridades distintas de tribunales judiciales, administrativos o del trabajo, emanen de un procedimiento en forma de juicio, el amparo sólo procede en contra de la resolución definitiva, debe interpretarse de manera amplia la expresión "procedimiento en forma de juicio", comprendiendo aquellos en que la autoridad dirime una controversia entre partes contendientes, así como todos los procedimientos en que la autoridad, frente al particular, prepara su resolución definitiva, aunque sólo sea un trámite para cumplir con la garantía de audiencia, pues si en todos ellos se reclaman actos dentro de procedimiento, en todos debe de aplicarse la misma regla, conclusión que es acorde con la interpretación literal de dicho párrafo. ${ }^{13}$

Todos los demás procedimientos administrativos que no deban cumplir con estos requisitos serán convencionales o de trámite constitutivo (permisos, licencias), regulativo (reglamentos o decretos) o declarativo (actas de matrimonio, defunciones), por lo tanto, en ellos no será necesario observar las formalidades del procedimiento. Ya que no se dirime un conflicto, por el contrario, se caracterizan en actos unilaterales que no requiere la intervención de voluntad del particular.

Para el caso del procedimiento previsto en la Ley General de Responsabilidades Administrativas, debemos catalogarlo como un procedimiento administrativo seguido en forma de juicio, por lo tanto, sus reglas deben estar dentro de los parámetros del artículo 14 de la Constitución Política de los Estados Unidos Mexicanos, a

13 Segunda Sala de la Suprema Corte de Justicia de la Nación (2003), jurisprudencia 2a./J. 22/2003, Semanario Judicial de la Federación y su Gaceta, Novena Época, Tomo XVII, Abril de 2003, p. 196. 
fin de no incurrir en formalismos procesales que trasciendan en el derecho de acceso a la justicia.

IV. Nuevo MOdelo DE PROCESo DE RESPONSABilidad ADMINISTRATIVA

En la Ley General de Responsabilidades Administrativas se establece un esquema totalmente novedoso para sancionar las faltas administrativas cometidas en el ejercicio del servicio público. En primer lugar, se prevé un catálogo de faltas graves y no graves, lo cual es relevante, ya que de acuerdo a la conducta, se definirá el tipo de procedimiento que deberá seguirse. Como conductas graves tenemos cohecho, peculado, desvío de recursos públicos, uso indebido de información, abuso de funciones, actuación bajo conflicto de intereses, contratación indebida, enriquecimiento oculto, tráfico de influencias, encubrimiento de faltas administrativas y desacato. ${ }^{14}$

Otra característica relevante, es que los particulares quedan sometidos a esta Ley, considerando como conducta grave cuando se participe o cometa soborno, participación ilícita en procedimientos administrativos, tráfico de influencias, utilización de información falsa, colusión, uso indebido de recursos públicos y contratación indebida. ${ }^{15}$

En general, el procedimiento se caracterizará por dos etapas, una etapa de investigación que puede iniciar de oficio, por denuncia o derivado de auditorías, ${ }^{16}$ en la cual la autoridad competente podrá realizar todo tipo de diligencias para recabar pruebas necesarias con la finalidad de hacerse de los elementos suficientes para iniciar

14 Artículos 51 a 64 de la Ley General de Responsabilidades Administrativas, vigente en 26 de octubre de 2017.

\footnotetext{
15 Idem., artículos 65 a 72.

16 Idem., artículo 91.
} 
con la segunda etapa, que sería propiamente el procedimiento de responsabilidad administrativa.

El procedimiento de responsabilidad inicia con el Informe de Presunta Responsabilidad Administrativa ${ }^{17}$ que realiza la autoridad investigadora y presentara ante la autoridad substanciadora, la cual podrá admitir, rechazar por falta de elementos o declarará que no existe responsabilidad. Hasta este momento debemos distinguir tres tipos de autoridades que intervienen en el procedimiento: investigadora, sustanciadora y resolutora, cuyas facultades se irán definiendo de acuerdo a la etapa del procedimiento. En el artículo 208 de la Ley de General de Responsabilidades Administrativas, se establece las formalidades que debe seguir el procedimiento; ${ }^{18}$ de las que

17 Idem., artículo.

18 Artículo 208. En los asuntos relacionados con Faltas administrativas no graves, se deberá proceder en los términos siguientes:

I. La Autoridad investigadora deberá presentar ante la Autoridad substanciadora el Informe de Presunta Responsabilidad Administrativa, la cual, dentro de los tres días siguientes se pronunciará sobre su admisión, pudiendo prevenir a la Autoridad investigadora para que subsane las omisiones que advierta, o que aclare los hechos narrados en el informe;

II. En el caso de que la Autoridad substanciadora admita el Informe de Presunta Responsabilidad Administrativa, ordenará el emplazamiento del presunto responsable, debiendo citarlo para que comparezca personalmente a la celebración de la audiencia inicial, señalando con precisión el día, lugar y hora en que tendrá lugar dicha audiencia, así como la autoridad ante la que se llevará a cabo. Del mismo modo, le hará saber el derecho que tiene de no declarar contra de sí mismo ni a declararse culpable; de defenderse personalmente o ser asistido por un defensor perito en la materia y que, de no contar con un defensor, le será nombrado un defensor de oficio;

III. Entre la fecha del emplazamiento y la de la audiencia inicial deberá mediar un plazo no menor de diez ni mayor de quince días hábiles. El diferimiento de la audiencia sólo podrá otorgarse por causas de caso fortuito o de fuerza mayor debidamente justificadas, o en aquellos casos en que se nombre;

IV. Previo a la celebración de la audiencia inicial, la Autoridad substanciadora deberá citar a las demás partes que deban concurrir al procedimiento, cuando menos con setenta y dos horas de anticipación;

V. El día y hora señalado para la audiencia inicial el presunto responsable rendirá su declaración por escrito o verbalmente, y deberá ofrecer las pruebas que estime necesarias 
podemos observar que se cumple con todas las formalidades del procedimiento, que van desde la notificación del probable infractor, la posibilidad de declarar, ofrecer pruebas, desahogarlas y alegar. El procedimiento se desahogará en dos audiencias: a) Audiencia inicial para rendir declaración y ofrecer pruebas; b) Audiencia de desahogo de pruebas.

Todo el procedimiento será desarrollado por la autoridad sustanciadora, que tendrá una naturaleza netamente administrativa. Sin embargo, si la conducta que se pretende sancionar es catalogada como grave, intervendrá una tercera autoridad, que se le denominará resolutora, contando con esa facultad el Tribunal Federal de Justicia Administrativa, a través de Salas Especializadas en Responsabilidad Administrativa, que:

Resolverán respecto de las faltas administrativas graves, investigadas y substanciadas por la Auditoría Superior de la Federación y los órganos internos de control respectivos, según sea el caso, ya sea que el procedimiento se haya seguido por denuncia, de oficio o derivado de las auditorías practicadas por las autoridades competentes (38, A, fracción I, de la Ley Orgánica del Tribunal Federal de Justicia Administrativa).

La intervención de la Sala tendrá lugar hasta después de celebrada la audiencia inicial, momento en que la autoridad resolutora remitirá las actuaciones a la Sala, la cual determinará si es competente para conocer del asunto, de considerarlo así, continuará con el desarrollo de procedimiento hasta su conclusión.

para su defensa. En caso de tratarse de pruebas documentales, deberá exhibir todas las que tenga en su poder, o las que no estándolo, conste que las solicitó mediante el acuse de recibo correspondiente. Tratándose de documentos que obren en poder de terceros y que no pudo conseguirlos por obrar en archivos privados, deberá señalar el archivo donde se encuentren o la persona que los tenga a su cuidado para que, en su caso, le sean requeridos en los términos previstos en esta Ley; 


\title{
v. Procedencia del juicio de amparo contra actos de AUTORIDADES ADMINISTRATIVAS
}

\begin{abstract}
Parafraseando al experto en Amparo, Raúl Chávez Castillo (2004), el Juicio de Amparo es un juicio constitucional, que se inicia por la acción que ejercita cualquier persona ante los tribunales de la Federación en contra de una ley o acto de autoridad, en las hipótesis previstas en el artículo 103, constitucional, que considere violatorio
\end{abstract}

VI. Los terceros llamados al procedimiento de responsabilidad administrativa, a más tardar durante la audiencia inicial, podrán manifestar por escrito o verbalmente lo que a su derecho convenga y ofrecer las pruebas que estimen conducentes, debiendo exhibir las documentales que obren en su poder, o las que no estándolo, conste que las solicitaron mediante el acuse de recibo correspondiente. Tratándose de documentos que obren en poder de terceros y que no pudieron conseguirlos por obrar en archivos privados, deberán señalar el archivo donde se encuentren o la persona que los tenga a su cuidado para que, en su caso, le sean requeridos;

VII. Una vez que las partes hayan manifestado durante la audiencia inicial lo que a su derecho convenga y ofrecido sus respectivas pruebas, la Autoridad substanciadora declarará cerrada la audiencia inicial, después de ello las partes no podrán ofrecer más pruebas, salvo aquellas que sean supervenientes;

VIII. Dentro de los quince días hábiles siguientes al cierre de la audiencia inicial, la Autoridad substanciadora deberá emitir el acuerdo de admisión de pruebas que corresponda, donde deberá ordenar las diligencias necesarias para su preparación y desahogo;

IX. Concluido el desahogo de las pruebas ofrecidas por las partes, y si no existieran diligencias pendientes para mejor proveer o más pruebas que desahogar, la Autoridad substanciadora declarará abierto el periodo de alegatos por un término de cinco días hábiles comunes para las partes;

$\mathrm{X}$. Una vez trascurrido el periodo de alegatos, la Autoridad resolutora del asunto, de oficio, declarará cerrada la instrucción y citará a las partes para oír la resolución que corresponda, la cual deberá dictarse en un plazo no mayor a treinta días hábiles, el cual podrá ampliarse por una sola vez por otros treinta días hábiles más, cuando la complejidad del asunto así lo requiera, debiendo expresar los motivos para ello;

XI. La resolución, deberá notificarse personalmente al presunto responsable. En su caso, se notificará a los denunciantes únicamente para su conocimiento, y al jefe inmediato o al titular de la dependencia o entidad, para los efectos de su ejecución, en un plazo no mayor de diez días hábiles. 
de sus derechos humanos, teniendo por objeto la declaración de inconstitucionalidad, restituyéndolo en el goce del derecho violado. ${ }^{19}$

El Juicio de Amparo tiene su fundamento constitucional en lo artículo 103 y 107, se trata de un juicio extraordinario, cuya litis se traduce en determinar la constitucionalidad de un acto de autoridad, por lo tanto, es un medio de control concentrado constitucional que dota al Poder Judicial de la Federación con facultades para hacer cumplir nuestra Carta Magna.

A pesar de tener fundamento internacional en el artículo 25 de la Convención Americana de Derechos Humanos, la cual, exige la creación de un recurso sencillo y rápido, es necesario decir que ni es un recurso y menos aún sencillo y rápido. Por el contrario, se trata de un juicio con una serie de reglas que lo vuelven demasiado técnico y preciso.

Entre la multiplicidad de actos de autoridad que pueden ser sometidos a control a través del Juicio de Amparo, tenemos los actos de naturaleza administrativa, que la Ley de Amparo, define como aquellos "actos u omisiones que provengan de autoridades distintas de los tribunales judiciales, administrativos o del trabajo". ${ }^{20}$ Es importante aclarar que esta hipótesis no necesariamente se refiere solo a actos de índole administrativa, puesto que también ubicaríamos los actos realizados por particulares equiparables a autoridades.

Sin embargo, recordemos que realizamos la distinción entre procedimientos administrativos y procedimientos administrativos seguidos en forma de juicio; y, en este último ubicamos el procedimiento de responsabilidad administrativa. Por lo cual, le es aplicable una regla adicional, que se ubica en la fracción III del numeral 107 de la Ley de Amparo, en la que indica que el amparo procederá:

19 Chávez Castillo, Raúl. Tratado Teórico Práctico del Juicio de Amparo, $4^{\mathrm{a}}$ ed., Porrúa, México, 2016, p. 23.

20 Artículo 107, fracción II, de la Ley de Amparo. 
III. Contra actos, omisiones o resoluciones provenientes de un procedimiento administrativo seguido en forma de juicio, siempre que se trate de:

a) La resolución definitiva por violaciones cometidas en la misma resolución o durante el procedimiento si por virtud de estas últimas hubiere quedado sin defensa el quejoso, trascendiendo al resultado de la resolución; y

b) Actos en el procedimiento que sean de imposible reparación, entendiéndose por ellos los que afecten materialmente derechos sustantivos tutelados en la Constitución Política de los Estados Unidos Mexicanos y en los tratados internacionales de los que el Estado Mexicano sea parte; (107, fracción III, de la Ley de Amparo).

Entonces el Juicio de Amparo contra actos u omisiones derivados de procedimientos administrativos seguidos en forma de juicio, sólo procederá en dos circunstancias: a) contra la resolución final; b) contra actos intraprocesales que sean de imposible reparación.

Por imposible reparación, la propia ley señala que debemos entenderlo como aquellos actos que afectan derechos sustantivos tutelados en la Constitución o en Tratados Internacionales. Esos derechos sustantivos, son los derecho humanos sustanciales, es decir, quedan excluido los derecho humanos adjetivos, que son de naturaleza procesal, como la garantía de audiencia, debido proceso, defensa técnica, defensa adecuada, entre muchos otros.

Por el contrario, los derechos sustanciales serán aquellos que se ejercen fuera de un juicio o que no necesariamente deban ejercitarse en un procedimiento, por ejemplo, la dignidad, igualdad, libertad o la vida. La Suprema Corte de Justicia de la Nación lo explica del siguiente modo:

Esta interpretación se deduce de las dos condiciones que el legislador secundario dispuso para la promoción del amparo indirecto contra actos de imposible reparación dictados en el proceso o el procedimiento: la primera, consistente en la exigencia de que se trate de actos "que afecten materialmente derechos", lo que equivale a 
situar el asunto en aquellos supuestos en los que el acto autoritario impide el libre ejercicio de algún derecho en forma presente, incluso antes del dictado del fallo definitivo; y la segunda, en el sentido de que estos "derechos" afectados materialmente revistan la categoría de derechos "sustantivos", expresión antagónica a los derechos de naturaleza formal o adjetiva, derechos estos últimos en los que la afectación no es actual - a diferencia de los sustantivos - sino que depende de que llegue o no a trascender al desenlace del juicio o procedimiento, momento en el cual sus secuelas pueden consumarse en forma efectiva $[\ldots]^{21}$

Por lo tanto, será la naturaleza y efectos del acto u omisión de la autoridad, la que nos dará pauta para que el Juicio de Amparo pueda ser procedente y se logré estudiar el fondo del asunto. Como técnica jurídica en la defensa, es relevante identificar que actos pueden ser de imposible reparación dentro del procedimiento de responsabilidad administrativa, lo cual se establecerá líneas adelante.

No podemos desprendernos de las reglas de procedencia del juicio de amparo, ya que no basta con que el tipo de acto haga procedente el juicio de amparo, porque además existen reglas que determinarían la improcedencia del Juicio de Amparo.

Entre ellas, tenemos la definitividad, ${ }^{22}$ "que consiste en que previamente a la promoción del juicio constitucional el acto no sea susceptible de impugnación en la vía ordinaria por cualquier medio de defensa existente, porque de estar pendiente de resolver una instancia o el particular hay omitido recurrirlo en tiempo y forma legales, entonces el amparo será improcedente." ${ }^{23}$ Es decir, que sólo será procedente el juicio de amparo cuando el acto de

21 Pleno de la Suprema Corte de Justicia de la Nación (2014), jurisprudencia P./J. $37 / 2014$ (10a.), Gaceta del Semanario Judicial de la Federación, Décima Época, Libro 7, Junio de 2014, Tomo I, p. 39.

22 Artículo 61, fracciones XVIII, XIX y XX, de la Ley de Amparo.

23 Carranco Zúñiga, Joel (coord..). La improcedencia en el amparo administrativo, en El Juicio de Amparo en Materia Administrativa, Porrúa, $3^{a}$ ed., México, 2014, p. 103. 
autoridad haya sido recurrido en tiempo y forma, o bien, no exista recurso o medio de defensa que pueda modificarlo o revocarlo.

Este principio tiene una serie de excepciones, como lo son:
a) Actos prohibidos o urgentes; ${ }^{24}$
b) Actos que afecten la libertad personal;
c) Personas extrañas a juicio;
d) Cuando la procedencia del recurso se sujete a interpre- tación adicional o su fundamento sea insuficiente para determinarla;
e) Si en el recurso, juicio o medio de defensa legal que pro- ceda, no se prevé la suspensión o bien, se exigen mayores requisitos a los establecidos en la Ley de Amparo;
f) Si el acto carece de fundamentación;
g) Sólo se aleguen violaciones directas a la Constitución;
h) Cuando el recurso se encuentre en reglamento y no en la ley que lo funda. ${ }^{25}$

En conclusión, para acudir al Juicio de Amparo en contra de actos derivados de procedimientos administrativos seguidos en forma de juicio, debemos tomar en cuenta si es la resolución definitiva o un acto intraprocesal, y de serlo, debemos verificar que sea de imposible reparación; además, nunca debemos olvidar verificar si procede algún recurso o medio de defensa, porque de haberlos, tendremos que agotarlo previamente.

24 Actos que importen peligro de privación de la vida, ataques a la libertad personal fuera de procedimiento, incomunicación, deportación o expulsión, proscripción o destierro, extradición, desaparición forzada de personas o alguno de los prohibidos por el artículo 22 de la Constitución Política de los Estados Unidos Mexicanos, así como la incorporación forzosa al Ejército, Armada o Fuerza Aérea nacionales (61, XVIII, a), Ley de Amparo).

25 Artículo 61, fracciones XVIII, XIX y XX, de la Ley de Amparo. 
Vi. Medios de impugnación en el PRocedimiento de RESPONSABILIDAD ADMINISTRATIVA

En la Ley de Responsabilidades Administrativas, contamos con cuatro recursos: Revocación (art. 210), Reclamación (art. 213) Apelación (art. 215) y Revisión. El primero será procedente en contra de la resolución que determine la responsabilidad por conductas administrativas no graves y se contará con un plazo de quince días para interponerse, teniendo legitimación para hacerlo, solo el infractor. La interposición de este recurso es optativa.

El de reclamación procederá contra resoluciones intraprocesales, siendo las siguientes a) admitan, desechen o tengan por no presentado el Informe de Presunta Responsabilidad Administrativa, la contestación o alguna prueba; b) las que decreten o nieguen el sobreseimiento del procedimiento de responsabilidad administrativa antes del cierre de instrucción; y c) aquéllas que admitan o rechacen la intervención del tercero interesado (artículo 213 de la Ley General de Responsabilidades Administrativas, de aquí en adelante LGRA). Se tiene un plazo de cinco días para su interposición y lo resolverá la propia autoridad emisora. Se advierte que la interposición del recurso no es optativa.

La apelación que será el recurso con el que contará el infractor o terceros para impugnar la resolución emitida por las Salas Especializadas en el caso de conductas graves (art. 215 LGRA), que resuelve sobre la responsabilidad, el cual resolverá la Tercera Sección de la Sala Superior del Tribunal Federal de Justicia Administrativa. No se advierte que su interposición sea optativa.

Finalmente, la revisión es el medio con el que cuentan los Órganos internos de control de los entes públicos federales o la Auditoría Superior de la Federación, para impugnar la resolución final que emitan las Salas Especializadas, es decir, sólo para el caso de conductas graves. Será de naturaleza vertical, siendo competente 
para resolverlo los Tribunales Colegiados del Poder Judicial de la Federación.

\section{TÉCNICA JURÍdICA Y ARguMENTACIÓN}

Las reglas establecidas en la Ley General de Responsabilidades Administrativas, son el medio por el cual es posible determinar la procedencia del Juicio de Amparo, así como, la vía a elegir, que puede ser la Directa o la Indirecta.

Para las violaciones cometidas durante la etapa de investigación, sólo en el supuesto que generen afectaciones de imposible reparación - como podría ser la omisión de notificarse el inicio de la investigación, requerimientos, diligencias o inspecciones que afecten derechos sustanciales - será procedente el Juicio de Amparo Indirecto, al no darse los supuestos de procedencia del Juicio de Nulidad.

Una etapa procesal medular es el momento de la presentación del Informe de Presunta Responsabilidad Administrativa, el que podrá ser admitido, desechado o tenerse por no presentado. Será necesario agotar el recurso de reclamación. En contra de la determinación, sería procedente el juicio de amparo indirecto al tratarse de un acto que genera una afectación sustancial y que no podría ser reparada en la sentencia. Evidentemente la autoridad investigadora no podría presentar juicio de amparo.

En el caso previsto para el procedimiento de faltas administrativas graves, en el artículo 209, fracción I, de la Ley en comento, se faculta a la Sala Especializada a devolver los autos si considera que la conducta no es grave, o bien, devolverlos para que la autoridad investigadora reclasifique por otra conducta grave, dándole las directrices para su debida presentación. Ese acto es de imposible reparación, puesto que el Tribunal guía a la autoridad investigadora, dándole la oportunidad de subsanar sus vicios. En contra del 
mismo, no procede recurso alguno, por lo que sería procedente el Juicio de Amparo por la vía Indirecta.

Si el vicio derivare de la omisión o deficiencia en la notificación del Informe de Presunta Responsabilidad Administrativa, dependerá del momento en que se verifique; si fuera antes de resolver el procedimiento, será necesaria la interposición del incidente de nulidad del emplazamiento ante la propia autoridad administrativa, a fin de agotar la definitividad. Empero, si se tuviera conocimiento de esa violación una vez turnados los autos para el dictado de la resolución, seria procedente el juicio de amparo por la vía indirecta, sin necesidad de agotar el incidente de nulidad.

Para el caso de la admisión o desechamiento de pruebas, deberá agotarse el recurso de reclamación y si fuere reiterativo, nos encontraremos en dos supuestos:

a) En el caso de que fuere un procedimiento seguido por una falta no grave, deberá plantearse la violación en el juicio de nulidad, para eventualmente hacerlo el juicio de amparo directo.

b) b) Si se tratare de un procedimientos seguido por una falta grave, entonces, la técnica del juicio de amparo exigiría reiterarlo en el recurso de apelación interpuesto contra la sentencia, a pesar del que el artículo 214 de la LGRA señala que la resolución de la reclamación no admite recurso alguno; sin embargo, será necesario hacerlo para garantizar su estudio como violación procesal en el juicio de amparo.

Ahora bien, en contra de la resolución que resuelva sobre una falta administrativa no grave, el infractor tendrán la opción de interponer recurso de revocación, pero la interposición del juicio de nulidad será necesaria a fin de cumplir con la definitividad, para eventualmente acudir al juicio de amparo por la vía directa. No se 
advierte que el tercero pueda interponer el recurso, por lo tanto, éste deberá acudir al juicio de nulidad para cumplir con la definitividad.

En cambio, para el caso de la resolución dictada por una falta grave, se deberá agotar el recurso de apelación; y en contra de ésta procederá el juicio de amparo directo, al no tener posibilidades de procedencia en juicio de nulidad; atendiendo que el recurso de apelación lo resuelve una de las Secciones de la Sala Superior, por lo que resultaría inválido que un inferior analice la legalidad de la referida resolución.

Por último, en relación a la imposición de medidas cautelares, ${ }^{26}$ el artículo 127 de la LGRA establece que no procederá recurso. Por lo que en caso de la interposición de alguna de éstas, para el caso de procedimientos por faltas no graves, podría proceder juicio de nulidad o juicio de amparo, dependiendo del planteamiento realizado.

Por el contrario, para el supuesto de que las medidas sean decretadas en el procedimiento por faltas graves, al estarla imponiendo una Sala Especializada del Tribunal Federal de Justicia Administrativa, no sería procedente el Juicio Contencioso Administrativo, por lo que sería procedente el Juicio de Amparo Indirecto.

VIII. LA VALIDEZ DE LA NORMA Y LOS FORMALISMOS PROCESALES

En la Ley General de Responsabilidades Administrativas nos encontramos con un modelo procesal complejo, que ofrece medios de impugnación enunciativos, y que si bien, su procedencia resulta ser clara; también lo es, que al momento de visualizarlo a través de las reglas del Juicio de Amparo se torna en normas complejas y de difícil compresión.

El procedimiento de responsabilidades vigente trae como consecuencia que al pretender ejercer un medio de defensa constitucio-

26 Suspensión temporal, exhibición de documentos, apercibimiento de multa, embargo precautorio o las necesarias para evitar un daño irreparable a la Hacienda Pública Federal (art. 124 LGRA). 
nal, como lo es el Juicio de Amparo, se complique definir su procedencia, derivado de existir un procedimiento de responsabilidades que se desahoga por la vía administrativa (faltas no graves) y otro que se desenvuelve en la vía jurisdiccional (faltas graves); provocando que las opciones de defensa sean diversas, al contener cada vía formalidades diversas.

De este modo, sobre todo al probable infractor, se le da un tratamiento procesal diverso, según la magnitud de la falta cometida, sometiéndose a formalismos procesales que merman su defensa, complicando el ejercicio efectivo del derecho de acceso a la justicia; al extremo que el infractor por faltas no graves cuenta con mayores oportunidades de defensa, pues tiene la posibilidad de acudir al Juicio de Nulidad. En cambio, si se trata del infractor por faltas graves, éste no tendrá la posibilidad de acudir al juicio de nulidad.

Claramente, existe un tratamiento distinto para un infractor y para el otro, condicionando el trato a la probabilidad de que haya cometido la infracción, lo cual nos lleva a poner en escrutinio la validez del procedimiento de responsabilidad administrativa. Que para la conclusión de este trabajo, cabe decir que el procedimiento es sustancialmente inválido, ya que sus reglas prevén formalidades distintas, basadas en un criterio de presunción de culpabilidad. Porque el tratamiento diferenciado para desde el momento de la presentación del Informe de Presunta Responsabilidad.

Por lo tanto, es necesario que al momento de acudir al Juicio de Amparo, este trato diferenciado sea planteado como inconstitucional, a fin de que al imputado por faltas graves, pueda beneficiarse de aquellas ventajas procesales que goza el imputado por faltas no graves.

\section{ix. Conclusiones}

La reforma en materia de responsabilidades administrativas fue una reacción ante el fenómeno social de la corrupción, no bastando 
regular las conductas de los servidores públicos, sino también de los particulares, con lo cual, surgieron nuevos procedimientos para ventilar las responsabilidades de los mismos.

Tales procedimientos deben estar ajustados a los principios constitucionales, en este caso, los derechos fundamentales y garantías constitucionales de los presuntos responsables, en equilibrio con los derechos fundamentales de la colectividad y los fines del Estado, como lo es la eficacia, eficiencia y transparencia en la aplicación del gasto público.

El procedimiento administrativo instituido, a pesar de perseguir un fin válido, incurre en una serie de formalismos jurídicos que complican el ejercicio de la defensa de los probables infractores, sometiéndolos a la toma de una serie de decisiones procesales complejas, que generan un alto margen de incurrir en un error, cuyo coste recaería en el resultado del procedimiento.

De este modo, el ejercicio de la defensa constitucional, como es el juicio de amparo, se torna complejo, al punto que puede convertirse en un medio de defensa de difícil acceso y ejercicio, contraviniendo el derecho de acceso a la justicia. Conforme a ello nos encontramos ante un procedimiento plagado de formulismos procesales.

Finalmente, el procedimiento de responsabilidades administrativas resulta en discriminatorio, al dar un tratamiento procesal diverso entre los imputados por faltas administrativas graves y las no graves. Por lo tanto, será necesario que a través de la interpretación constitucional, el procedimiento administrativo en estudio se vaya uniformando y ajustando a los márgenes constitucionales, para garantizar seguridad jurídica entre los diversos factores interesados o afectados por el actual sistema de responsabilidades administrativas.

Por lo que será necesario delimitar adecuadamente la competencia de los Tribunales Administrativos a fin de que actúen de manera imparcial y prevalezca el principio de igualdad procesal. Asimismo, será necesario establecer los mismos parámetros de defensa para ambos procedimientos administrativos. 
Por el momento, será necesaria la capacidad y conocimientos del abogado defensor, como las aquí recomendadas, a fin de garantizar a los probables infractores un acceso efectivo a la justifica y un derecho a una defensa técnica.

\section{x. Bibliografía}

Alexy, Robert, Ponderación, control de constitucionalidad y representación, México, UNAM, Instituto de Investigaciones Jurídicas, 2006.

Garranco Zúñiga, Joel (coord..). La improcedencia en el amparo administrativo, en El Juicio de Amparo en Materia Administrativa, Porrúa, $3^{a}$ ed., México, 2014.

Chávez Castillo, Raúl. Tratado Teórico Práctico del fuicio de Amparo, $4^{\mathrm{a}}$ ed., Porrúa, México, 2016.

Ferrajoli, Luigi, Principia Iuris. Teoría del Derecho y de la Democracia. Parte I. Colección Estructuras y Procesos. Serie Derecho, Trotta, Italia, 2011.

- Luigi, Los fundamentos de los derechos fundamentales, España $4^{\mathrm{a}}$. ed., trad. Andrés Perfecto, Antonio de Cabo, et al., Trotta, 2009.

Fraga, Gabino, Derecho Administrativo, Porrúa, 48 a ed., México 2012.

Ovalle Favela, José. Teoría general del proceso, $6^{a}$ edición, Oxford, México, 2011.

Pérez Fernández del Castillo, Germán y León y Ramírez, Juan Carlos, El léxico de la política en la globalización, Universidad Nacional Autónoma de México, Facultad de Ciencias Políticas y Sociales, México, 2008.

\section{Otros materiales de consulta}

Cortés Campos, Josefina, Kaiser Aranda Max y Roldá Xopa, José, Iniciativa Ciudadana de la Ley General de Responsabilidades Administrativas, México, recuperado el 25 de octubre de 2017, de <http:// ley3de3.mx/wp-content/uploads/2016/02/Ley3de3_LEY_IniciativaCiudadanaDeLeyGeneralDeResponsabilidadesAdministrativas_Documento.pdf>. 
Dag Einar Thorsen and Amund Lie. What is Neoliberalism?, Department of Political Science University of Oslo, Noruega, 2010, consultado en <http://folk.uio.no/daget/What $\% 20$ is $\% 20$ Neo-Liberalism $\% 20$ 10-11-06.pdf>.

Grupo parlamentario del Partido Acción Nacional en la Cámara de Senadores (2015), Exposición de Motivos para la Iniciativa con proyecto de decreto por el que se expide la Ley General del Sistema Nacional Anticorrupción, recuperado el 25 de octubre de 2017, de <http://www.senado.gob.mx/comisiones/anticorrupcion/docs/ corrupcion/PAN_LGSNA.pdf $>$.

Diccionario de la Real Academia Española, España, 2017, consultado en $<$ http://dle.rae.es>. 